Rec. Nat. Prod. 15:5 (2021) 368-379

records of natural

A C G

Rec. Nat. Prod. 15:5 (2021) 368-379

products

publications

\title{
New Selective Human MAO-B Inhibitors from the Stems of Erythrina corallodendron $\mathrm{L}$.
}

\author{
Mohamed Aboelmagd $\mathbb{C}^{1,2}$, Khaled M. Elokely ${ }^{3,4}$, Ataa Said ${ }^{2}$, \\ Eman G. Haggag ${ }^{5}$, Mohammed M. Ghoneim ${ }^{6,7^{*}}$ \\ and Samir A. Ross ${ }^{1,8^{*}}$
}

${ }^{I}$ National Center for Natural Product Research, School of Pharmacy, The University of Mississippi, University, MS 38677, USA

${ }^{2}$ Pharmacognosy Department, National Research Centre, Dokki, Giza,12622, Egypt

${ }^{3}$ Department of Pharmaceutical Chemistry, Tanta University, 31527 Tanta, Egypt

${ }^{4}$ Department of Chemistry and Institute for Computational Molecular Science, Temple University, Philadelphia, PA 19122, USA

${ }^{5}$ Pharmacognosy Department, Faculty of Pharmacy, Helwan University, Helwan, Cairo 11795, Egypt

${ }^{6}$ Department of Pharmacy, College of Pharmacy, AlMaarefa University, Ad Diriyah, Riyadh 13713, Saudi Arabia

${ }^{7}$ Department of Pharmacognosy, Faculty of Pharmacy, Al-Azhar University, Cairo, 11371, Egypt

${ }^{8}$ Department of BioMolecular Sciences, Pharmacognosy Division, School of Pharmacy, The University of Mississippi, University, MS 38677, USA

(Received January 11, 2021; Revised February 17, 2021; Accepted March 05, 2021)

\begin{abstract}
One new, 10, 11-dioxo-6,7 $\alpha$-erythraline epoxide (1) and four known erythrinan alkaloids 10, 11-dioxoerythraline (2), erysodine (3), 8-oxo-erythraline (4) and erythraline (5) were isolated from the $70 \%$ methanolic extract of stems of E. Corallodendron (Fabaceae). The isolated compounds were elucidated by exploiting 1D/2D NMR, and HR-ESI-MS analysis. The absolute configuration of 1 was determined by electronic circular dichroism (ECD). Mono Amine Oxidase inhibitory activity of the isolated alkaloids was investigated in vitro using kynuramine deamination assay on recombinant human MAO-A and B enzymes. The binding modes were predicted by molecular docking and the structure activity relationships of erythrinans were then evaluated. All isolated alkaloids demonstrated preferential activity against MAO-B. 1 displayed the highest potency and selectivity against MAO-B with $\mathrm{IC}_{50}$ of $25.18 \mu \mathrm{M}$, (SI >3.97). The selective inhibition exhibited by erythrinan alkaloids against MAO-B is in line with the expected biological impact of Erythrina in the treatment of neurodegenerative diseases and presents this chemical class as promising leads for managing AD and PD diseases.
\end{abstract}

Keywords: Erythrina corallodendron; alkaloids; Alzheimer's disease; Parkinson's disease; selective MAO-B inhibitors; docking. (C) 2021 ACG Publications. All rights reserved.

\section{Introduction}

Alzheimer's disease (AD) is one of most devastating neurodegenerative disease, affecting more than 25 Million people worldwide, which end with death in the average of 9 years after diagnosis [1]. In the USA, it considered the sixth leading cause of death [1]. Parkinson's disease (PD) is the $2^{\text {nd }}$ common

\footnotetext{
* Corresponding author: E- Mail: mghoneim@mcst.edu.sa; (MMG) Phone: +966-537415011 and sross@olemiss.edu, (SAR) Phone: 1-662-9011031
} 
neurodegenerative disorder with a worldwide prevalence of about $0.3 \%$ of the population; with deterioration of the motor functions. It was estimated that the mortality rate associated with PD is 1.52.4, which resulted from the disease complications [2]. The need for alternative strategies to tackle and modify AD and PD by alternate mechanisms is highly required.

Monoamine oxidases are metabolizing enzyme systems responsible for the oxidative deamination of the monoamine neurotransmitters. According to substrate specification they are divided into two isoforms MAO-A and B. The increased activity of MAOs especially in the elderly population has been recently involved in the pathogenesis not only the neurodegenerative diseases but also in other disorders such as heart failure [3]. MAO-B is located mainly in human brain and its level is increased up to three times in elderly people. A solid relation between the elevated MAO-B level and the increased precipitation of plaques into neurons of AD's patients as well as the neuronal cell death is well proved [4]. The formation of 1-methyl-4-phenylpyridium ion $\left(\mathrm{MPP}^{+}\right)$, a potent neurotoxin in the $\mathrm{PD}$, is catalyzed mainly by MAO-B, consequently MAO-B inhibitors could modify PD progression by decreasing $\mathrm{MPP}^{+}$-related neurotoxicity [5]. Additionally, MAO-B inhibitors could also act as a mono therapy in the early stage treatment of PD by increasing the availability of dopamine (DA) and also as a first line alternative to dopamine agonists and L-DOPA avoiding their known motor side effects [6,7]. For these reasons the inhibition of MAO-B is now considered as an important target for the treatment of neurodegenerative diseases mainly $\mathrm{AD}$ and $\mathrm{PD}$ for elderly population [7]. Genus Erythrina is belonging to family Fabaceae, it has well-known neurological activity in the folk medicine as a treatment of anxiety, insomnia, convulsion and AD [16]. Many Erythrina species have been proved to have CNS activity as tranquilizer, anticonvulsant [9-12], and anxiolytic [13], also a neuroprotective activity against a PD neurotoxin 6-hydroxydopamine [14], and against Trypanosoma induced meningoencephalitis [15], further more acetylcholine releasing activity alleviating the AD symptoms [13]. Further studies revealed that the anti-convulsion, hypnotic and anxiolytic activities were suggested to be related to erythrinan alkaloids $[12,17,18]$. Despite of the known neurological properties of Erythrina but to the best of our knowledge this study is the first that examine the MAO inhibition potentiality of erythrinan alkaloids. In this study, we evaluated a series of erythrinan alkaloids isolated from the methanolic extract of E. corallodendron stems against recombinant human monoamine oxidase enzymes using in vitro study accompanied with modeling study to illustrate the proposed mechanism of interaction of erythrinans with the MAO receptor.

\section{Materials and Methods}

\subsection{General Procedure}

The chromatographic separation was carried out on open column chromatography using standard silica gel (40-63 $\mu \mathrm{m}, 230-400$ mesh, Sorbent Technologies) reversed phase (RP-C18) silica gel (0.04 $0.063 \mathrm{~mm}$, mesh size, Merck, Germany) and Sephadex LH-20 (0.25 - $0.1 \mathrm{~mm}$, mesh size, Mitsubishi Kagaku, Tokyo, Japan). Precoated silica gel $60-\mathrm{F}_{254},(0.25 \mathrm{~mm})$ plates for thin layer chromatography. Vanillin/ $\mathrm{H}_{2} \mathrm{SO}_{4}(10 \% \mathrm{v} / \mathrm{v}$ conc. sulphuric acid in ethanol) and Dragendorff's reagent, Fluka, spraying agent for visualization spots on TLC plates. The ${ }^{1} \mathrm{H}$ and ${ }^{13} \mathrm{C}$ NMR experiments were carried out on Bruker AMX-400 and $500 \mathrm{MHz}$ NMR spectrometer at standard pulse sequence $400,500 \mathrm{MHz}$ for ${ }^{1} \mathrm{H}$ and $100,125 \mathrm{MHz}$ for ${ }^{13} \mathrm{C}$ NMR respectively, $\mathrm{CDCl}_{3}$ and DMSO were used as solvent, the DEPT and 2D-NMR experiments (HMQC, HMBC, NOSEY) carried out using standard Bruker pulse programs. The optical rotation was measured on Rudolph Research Analytical Autopol IV automatic polarimeter, the ECD data were measured using Olis Cary-17 spectrophotometer. The HR-ESI-MS was recorded on Bruker Bioapex-FTMS, direct injection with electrospray ionization. Recombinant Human MAO-A and MAO-B were obtained from BD Biosciences (Bedford, MA, USA), drug control, Clorgyline, Deprenyl, Phenelzine, (positive control) and DMSO (negative control) were purchased from Sigma Chemical (St. Louis, MO, USA). The MAO inhibition assay was carried on Spectra- Max M5 fluorescence plate reader (Molecular Devices, Sunnyvale, CA, USA). 


\subsection{Plant Material}

The stems of Erythrina corallodendron were collected from El-Zohria botanical garden-Giza-Egypt in March 2012 and it was identified by Prof. Dr. Salwa El-Kawatchy, Department of systematic plant taxonomy, The National Research Centre, Cairo, Egypt. A voucher specimen (No. M125) was preserved in the herbarium of The National Research Centre (CAIRC), Cairo, Egypt.

\subsection{Extraction and Isolation}

The powdered air-dried stems of E. corallodendron $(2 \mathrm{~kg})$ was extracted by maceration in methanol $70 \%(10 \mathrm{~L} \times 3)$ at room temperature. The combined methanolic extracts were evaporated under reduced pressure to afford $150 \mathrm{~g}$ crude methanolic extract which was mixed with $60 \mathrm{~g}$ Celite (by adsorbing the sample onto celite) and fractionated on $650 \mathrm{~g}$ silica gel reversed phase (RP-18) using vacuum liquid chromatography (RP-18VLC), eluted with $\mathrm{H}_{2} \mathrm{O}: \mathrm{MeOH}$ mixtures of decreasing polarities starting with $100 \% \mathrm{H}_{2} \mathrm{O}$ then $\mathrm{MeOH}$ was increasing gradually $(20 \%, 40 \%, 50 \%, 75 \%$ and $100 \%)(\mathrm{S}-1)$ system. The resulted fractions were screened on silica gel thin layer chromatographic plates (TLC) sprayed with vanillin- $\mathrm{H}_{2} \mathrm{SO}_{4}$ and Dragendorff's spraying agents. Accordingly, four combined fractions were obtained A-D. Fractions B (1.3 g) and C (3.1 g) each of them was further fractionated on $75 \mathrm{~g}$ silica gel (RP-18 VLC) eluted with S-1system resulted in five main subfractions each. Subfraction B-2 subjected to further separation on Sephadex LH-20 Column Chromatography (CC) eluted with $100 \% \mathrm{MeOH}$, followed by silica gel CC using DCM: MeOH eluting system 99:1-19:1 affording compound 1(1.4 mg) new alkaloid. Both subfractions C-2 and C-3 were fractionated on Sephadex LH-20 CC eluted with 100\% MeOH, followed by silica gel CC using DCM: MeOH eluting system 99:1-19:1 to afford 3 (10mg), 2 (1.5mg), 4 (2mg) and 5 (4mg), respectively.

Compound 1 was obtained as amorphous solid $(1.4 \mathrm{mg}),[\alpha]_{D}^{25}:+100 \mathrm{MeOH}\left(c 5 \times 10^{-2}\right)$ HR-ESIMS, $[\mathrm{M}+\mathrm{H}]^{+}$at $\mathrm{m} / \mathrm{z}$ 342.0991, (calcd. For $\left.\mathrm{C}_{18} \mathrm{H}_{16} \mathrm{NO}_{6}, 342.0978\right), \mathrm{CD}(\mathrm{MeOH}) \lambda(\theta): 220.6\left(-147 \times 10^{3}\right)$, $312.8\left(6 \times 10^{3}\right) \mathrm{nm} .{ }^{1} \mathrm{H}$ and ${ }^{13} \mathrm{C}$ NMR data (table 1$)$.

\subsection{Monoamine Oxidase Inhibitor Assay}

The inhibitory activity of the isolated erythrinans (1-5) from E. corallodendron stems were evaluated in vitro by applying the kynuramine deamination assay on human recombinant MAO-A and B enzymes according to the previously reported method [19]. The inhibitory activity was calculated as percent of deamination product formation compared to the corresponding control (enzyme-substrate reaction) without inhibitors. Control assays were setup in the same instance after stopping the reaction with the isolated compounds to check their interference with the fluorescence measurements, (enzyme or substrate with isolated compound). The $\mathrm{IC}_{50}$ values for MAO-A and -B inhibition were calculated from the concentration dependent inhibition curves using XLFit software.

\subsection{Molecular Modeling Study}

\subsubsection{Conformational Search}

All proposed stereoisomers of the isolated compounds were sketched, converted into 3D and energy minimization in Maestro. Mixed torsional/low-mode sampling in MacroModel was used to construct all possible structural conformations. A maximum of 1000 steps to construct a unique conformer, and up to 100 steps for rotatable bond were selected for conformer generations. The maximum energy difference between the lowest and highest energy conformers was up to $10 \mathrm{kcal} / \mathrm{mol}$. To get rid of redundant conformers and to keep only unique ones, a root mean square deviation (RMSD) of less than $0.3 \AA$ was used to distinguish between similar conformers. Powell-Reeves conjugate gradient (PRCG) method was used for energy minimization of generated conformers setting a convergence threshold of 0.005 . This step was then followed by a second minimization to assure optimal geometry optimization. 


\subsubsection{Geometry Optimization and ECD Calculation}

The Boltzmann's population was calculated for each set of conformers to define the most abundant ones in the series. The B3LYP hybrid density functional method at 6-31G $(\mathrm{d}, \mathrm{p})$ basis set level(20) in Gaussian 09 (21) was used for geometry optimization step. The geometry optimized conformers were then subjected to the electronic circular dichroism (ECD) calculation using timedependent B3LYP density functional at 6-31G $(\mathrm{d}, \mathrm{p})$ basis set level with 40 excited states. The calculated ECD spectra were averaged based on the Boltzmann's distribution of each conformer using SpecDis. The calculated and experimental spectra were then compared for matching.

\subsection{Molecular Docking}

Molecular structures of the compounds were curated using LigPrep (LigPrep, Schrödinger, LLC: New York, NY, 2017). OPLS3 force field was used for molecular parameterization. Protonation and tautomerization states of ligands were generated at pH 7.4 using Epik [22, 23]. The stereochemical information was retained during this step and the lowest energy conformer for each ligand was generated. The protein complexes of MAO-A (PDB ID: 2Z5X) (24) and MAO-B (PDB ID: 4A7A) (25) were downloaded from the protein databank repository (www.pdb.org). Protein preparation wizard was utilized to prepare the protein complexes for docking [26] by adjusting atom types and bond orders, adding missing hydrogen atoms, filling in missing amino acid side chain and loops Prime $[27,28]$ and deleting water molecules beyond $5.0 \AA$ from ligand atoms. The hydrogen bonds network was analyzed by sampling water molecules and amino acid side chains orientation at $\mathrm{pH} 7.4$ using PROPKA to allow for their proper assignments. Water molecules that form more than three hydrogen bonds with non-water residues were kept. To reduce atomic clashes, protein complexes were energy minimized.

The ligand binding pocket of each protein complex was defined by the atomic coordinates of native ligand. Soft docking approach was applied via scaling the Van der Waals radii non-polar atoms by a factor of 0.8. A partial charge cutoff of 0.25 was set. Standard precision (SP) docking option was used. The docking poses were ranked and the best scoring one was selected for further investigation.

\section{Results and Discussions}

\subsection{Structure Elucidation}

The phytochemical study of the $70 \%$ methanolic extract of E. corallodendron stems resulted in isolation of one new 10,11-dioxo-6,7 $\alpha$-erythraline epoxide (1) and four known erythrinan alkaloids: 10 , 11-dioxo-erythraline (2) [29], erysodine (3) [30], 8-oxo-erythraline (4) [31] and erythraline (5) [30] (Figure 1). The ${ }^{1} \mathrm{H}$ and ${ }^{13} \mathrm{C}$ NMR spectral data and HRESIMS (see supplementary data) of the known compounds are in good agreement with the previously published data [31]. The orientation of the epoxy group in compound A1 was determined by the 2D NOESY experiment, where cross peak correlations between $\mathrm{H}-7 / \mathrm{H}-1, \mathrm{H}-1 / \mathrm{H}-2, \mathrm{H}-2 / \mathrm{H}-3$ were detected (Figure 2). Biogenetically the H-3 exhibited $\beta$ configuration as all erythrinan alkaloids [29], which indicates cis conformation of both epoxy ring and methoxy group at C-3 position. Further confirmation obtained by the molecular modeling study which revealed that the most abundant conformers of the optimized structure of compound A1 displayed cis orientation of both groups (Figure 3). The Absolute configuration of C-7 was determined to be $S$ by the $\mathrm{CD}$ experiment accompanied with the ECD calculation. The experimental CD curve matches with the calculated curve of $(6,7 \mathrm{R}, \mathrm{S})$ conformer with -ve cotton effect at $\sim 230 \mathrm{~nm}$ (Figure 4), furthermore the positive sign of the optical rotation value of compound A1 indicating that the absolute configuration of C-3 is $R$ and C-5 is $S[29,33]$. 
<smiles>CO[C@@H]1C=C[C@]23O[C@H]2CN2C(=O)C(=O)c4cc5c(cc4[C@]23C1)OCO5</smiles>

1<smiles>[R3]C1C=C2C=C[C@H](OC)CC23c2cc4c(cc2C([R])N1C([R2])C3[R])OCO4</smiles>

$2 \mathrm{R}_{1}=\mathrm{R}_{2}=\mathrm{O}, \mathrm{R}_{3}=\mathrm{H} 2$

$4 \mathrm{R}_{1}=\mathrm{R}_{2}=\mathrm{H} 2, \mathrm{R}_{3}=\mathrm{O}$

$5 \quad \mathrm{R}_{1}=\mathrm{R}_{2}=\mathrm{R}_{3}=\mathrm{H} 2$<smiles>C=C[C@@H](CC12C=CCN1CCc1cc(O)c(OC)cc12)OC</smiles>

3

Figure 1. Chemical structures of isolated erythrinan alkaloids from E. corallodendron

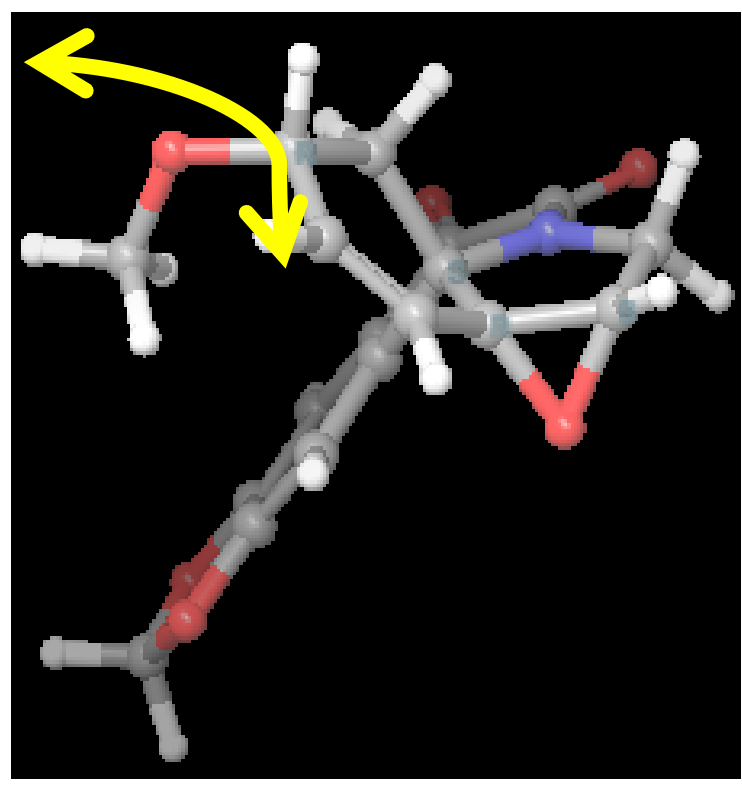

Figure 2. Optimized structure of $\mathbf{1}$ with key NOESY correlation between $\mathrm{H}-7$ and H-3
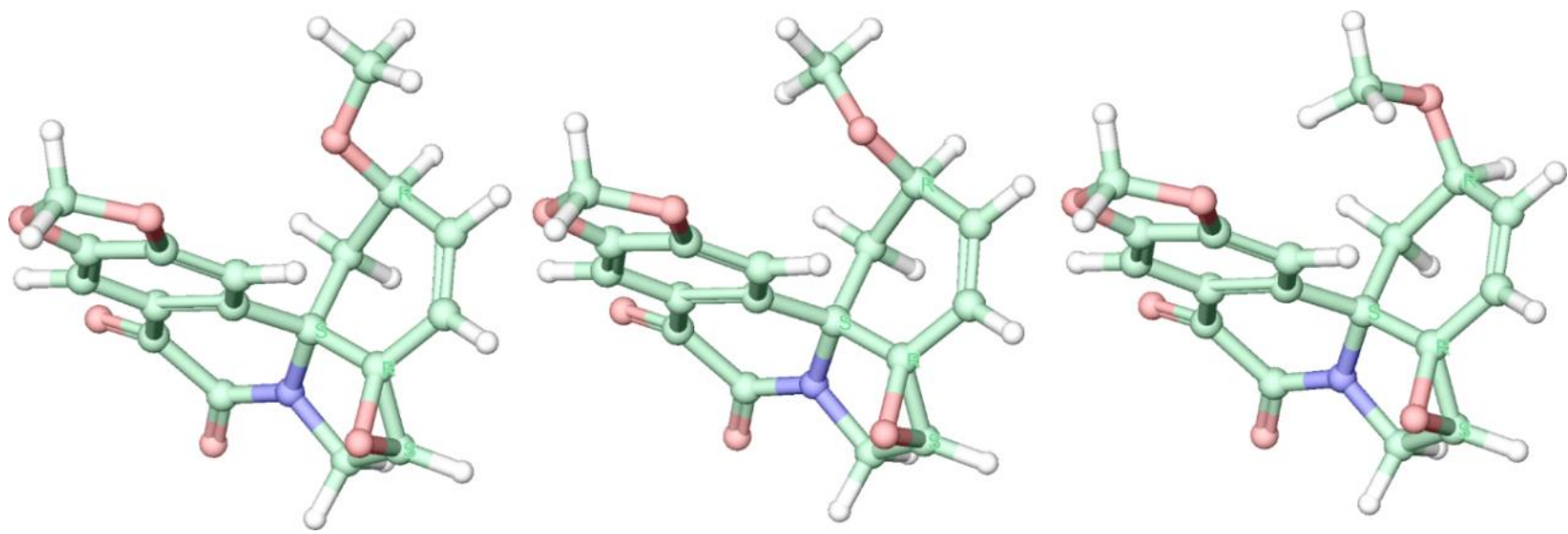

Figure 3. The most abundant conformers of the optimized structure of compound 1 


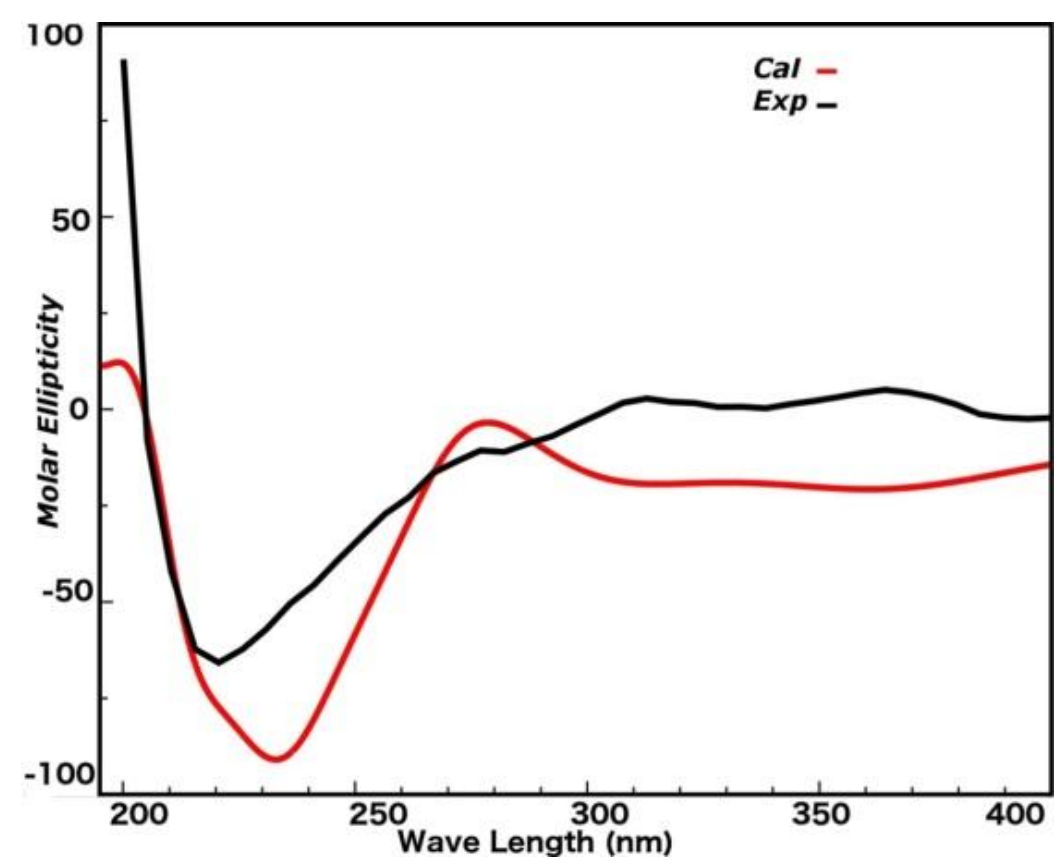

Figure 4. ECD calculated curve of the compound 1 matched with the experimental curve in black with negative cotton effect at $\sim 230 \mathrm{~nm}$

Compound 1 was obtained as amorphous solid $(1.4 \mathrm{mg}),[\alpha]_{D}^{25}:+100 \mathrm{MeOH}\left(c 5 \times 10^{-2}\right)$, the molecular formula was confirmed to be $\mathrm{C}_{18} \mathrm{H}_{15} \mathrm{NO}_{6}$ from the HR-ESI-MS which showed quasimolecular ion peaks $[\mathrm{M}+\mathrm{H}]^{+}$at $\mathrm{m} / \mathrm{z}$ 342.0991, (calcd. 342.0978). The ${ }^{1} \mathrm{H}$ NMR (Table 1) spectrum showed the main features of erythrinan alkaloids, the biogenetic methoxy group appeared at $\delta_{H} 3.02$ $(3 \mathrm{H}, \mathrm{s}, \mathrm{OMe})$ [29], two ortho coupled olefinic proton signals at $\delta_{H} 5.91(1 \mathrm{H}, \mathrm{dd}, J=10.4,2.4 \mathrm{~Hz}, \mathrm{H}-1)$, $\delta_{H} 6.33(1 \mathrm{H}, \mathrm{d}, J=10.4 \mathrm{~Hz} \mathrm{H}-2), \mathrm{AX}_{2}$ system represented by nitrogen bearing methylene protons which resonated at $\delta_{H} 3.87(1 \mathrm{H}, \mathrm{dd}, J=11.6,1.2 \mathrm{~Hz}, \mathrm{H}-8 \beta), \delta_{H} 4.2(1 \mathrm{H}, \mathrm{d}, J=11.6 \mathrm{~Hz}, \mathrm{H}-8 \alpha)$ and coupled with methine proton signal at $\delta_{H} 3.75(1 \mathrm{H}, \mathrm{d}, J=1.2 \mathrm{~Hz}, \mathrm{H}-7)$, multiplet signal at $\delta_{H} 3.8(1 \mathrm{H}, \mathrm{m}, \mathrm{H}-3)$ corresponding to oxymethine proton and methylene protons $\delta_{H} 2.24(1 \mathrm{H}, \mathrm{dd}, J=5,1.2 \mathrm{~Hz}, \mathrm{H}-4 \mathrm{e}), \delta_{H}$ $2.31(1 \mathrm{H}, \mathrm{d}, J=10, \mathrm{~Hz}, \mathrm{H}-4 \mathrm{a})$. The spectrum displayed two singlet para aromatic protons at $\delta_{H} 7.27$ $(1 \mathrm{H}, \mathrm{s}, \mathrm{H}-14), \delta_{H} 7.47(1 \mathrm{H}, \mathrm{s}, \mathrm{H}-17)$, two proton signals resonating at $\delta_{H} 6.12\left(1 \mathrm{H}, \mathrm{d}, J=1.2 \mathrm{~Hz}, \mathrm{OCH}_{2} \mathrm{O}\right)$, $\delta_{H} 6.13\left(1 \mathrm{H}, \mathrm{d}, J=1.2 \mathrm{~Hz}, \mathrm{OCH}_{2} \mathrm{O}\right)$, corresponding to methylenedioxy group, in pattern similar to erythraline alkaloid 5 [30] but with oxygenation at C-11 position and one olefinic proton missing $\mathrm{H}-7$ of the dienoid system which characterizes the erythrinan alkaloids. The ${ }^{13} \mathrm{C}$ NMR, DEPT and HMQC spectra displayed the same pattern of 2 but with one olefinic carbon at $\delta_{C} 121.3(\mathrm{C}-7)$ replaced with oxymethine carbon resonated at $\delta_{C} 59.5(\mathrm{C}-7)$, it showed also one oxygenated methine $\delta_{C} 74.5(\mathrm{C}-3)$, two aromatic methine $\delta_{C} 104.5(\mathrm{C}-14)$ and $\delta_{C} 108.6(\mathrm{C}-17)$ and two olefinic carbons $\delta_{C} 125.7(\mathrm{C}-1)$ and $\delta_{C} 136.6(\mathrm{C}-2)$, one methoxy $\delta_{C} 56.8$, two methylene signals $\delta_{C} 46.3(\mathrm{C}-4), \delta_{C} 46.2(\mathrm{C}-8)$ and one methylenedioxy group $\delta_{C} 102.8$, eight quaternary carbon signals $\delta_{C} 65.8(\mathrm{C}-5), \delta_{C} 66.3(\mathrm{C}-6), \delta_{C} 126.6$ $(\mathrm{C}-12), \delta_{C} 139.7(\mathrm{C}-13), \delta_{C} 150.2(\mathrm{C}-15) \delta_{C} 148.9(\mathrm{C}-16), \delta_{C} 156.6(\mathrm{C}-10)$, and $\delta_{C} 178.8(\mathrm{C}-11)$, Furthermore the mass displayed difference equal to one oxygen excess comparing to the $\mathbf{2}$ in addition to the upfield shift of C- $6 \delta_{C} 66.3$ and C-7 $\delta_{C} 59.5$ to the comparable chemical shift of C- $6 \delta_{C} 136.7$ and C-7 $\delta_{C} 121.3$ indicates the presence of epoxy ring in position 6,7 [29,34]. The HMBC spectrum displayed correlations H-8/C-6 and C-7, H-7/C-8, H-2/ C-3 and C-6, which provide more confirmation about the presence of epoxy ring in position $\mathrm{C}-6, \mathrm{C}-7$, it showed also these correlations $\mathrm{H}-1 / \mathrm{C}-3$ and $\mathrm{C}-5, \mathrm{H}-4 / \mathrm{C}-$ 3, C-5and C-13, H-14/C-12, C-15and C-16, H-17/C-13, C-15and C-16.

The spectral data are in good agreement with 10, 11-dioxo-erythrinan 2 [29] except the epoxide part of the molecule. From all the mentioned elucidation compound 1 was identified as 10, 11-dioxo- 6,7 $\alpha-$ erythraline epoxide. This is the $1^{\text {st }}$ report of isolation and identification of compound $\mathbf{1}$ in nature which is the first example of erythrinan alkaloids with epoxy at position C-6, C-7. 
Table 1. ${ }^{1} \mathrm{H}$ and ${ }^{13} \mathrm{C}$ NMR data of compound 1 in $\mathrm{CDCl}_{3}{ }^{*}$

\begin{tabular}{ccc}
\hline Position & $\boldsymbol{\delta}_{\boldsymbol{H} \text { ppm mult., } \boldsymbol{J}(\mathbf{H z})}$ & $\boldsymbol{\delta}_{\boldsymbol{C} \text { ppm }}$ \\
\hline 1 & $5.91 \mathrm{dd},(10.4,2.4)$ & 125.7 \\
2 & $6.33 \mathrm{~d},(10.4)$ & 136.6 \\
3 & $3.8 \mathrm{~m}$ & 74.5 \\
4 & $\mathrm{H}-4 \mathrm{e} 2.24 \mathrm{dd},(5)$ & 46.2 \\
& $\mathrm{H}-4 \mathrm{a} 2.31 \mathrm{~d},(10)$ & \\
5 & - & 65.8 \\
6 & - & 66.3 \\
7 & $3.75 \mathrm{~d},(1.2)$ & 59.5 \\
8 & $\mathrm{H}-8 \alpha 2 \mathrm{~d},(11.6)$ & 46.3 \\
& $\mathrm{H}-833.84 \mathrm{dd},(11.6,1.2)$ & \\
10 & - & 156.6 \\
11 & - & 178.8 \\
12 & - & 126.6 \\
13 & - & 139.7 \\
14 & 7.27 & 104.5 \\
15 & - & 148.2 \\
16 & - & 108.6 \\
17 & $7.47 \mathrm{~s}$ & 56.8 \\
$\mathrm{OCH}_{3}$ & 3.31 & 102.8 \\
$\mathrm{OCH}_{2} \mathrm{O}$ & $1 \mathrm{H} 6.12 \mathrm{~d},(1.2)$ & \\
& $1 \mathrm{H} 6.13 \mathrm{~d},(1.2)$ &
\end{tabular}

\subsection{MAO Inhibition}

The biological evaluation of the isolated alkaloids (1-5) against MAO enzymes displayed selective inhibitory properties towards MAO-B. The purity of the tested compounds has been confirmed from the potential of quantitative $1 \mathrm{H}$ NMR. The $\mathrm{IC}_{50}$ range from $(25-80 \mu \mathrm{M})$ and the order of inhibitory activity is $\mathbf{1}>\mathbf{2}>3>\mathbf{4}>\mathbf{5}$ (Table 2). All the isolated alkaloids exhibited $\mathrm{IC}_{50}$ values $>100$ against MAO-A. The new alkaloid 1 showed the highest activity $\mathrm{IC}_{50} 25.18 \mu \mathrm{M}$ accompanied with the highest selectivity index for MAO-B (SI) $>3.97$.

Table 2. The inhibitory activity of isolated erythrinans against MAO-A and B expressed in $\mu \mathrm{M}$

\begin{tabular}{cccccccc}
\hline Compounds & $\begin{array}{c}\text { MAO- } \\
\text { A IC }_{\mathbf{5 0}}\end{array}$ & $\begin{array}{c}\text { SD } \\
\text { value }\end{array}$ & $\begin{array}{c}\text { MAO-A } \\
\text { IC }_{\mathbf{9 0}}\end{array}$ & $\begin{array}{c}\text { MAO- } \\
\text { B IC }_{\mathbf{5 0}}\end{array}$ & SD value & $\begin{array}{c}\text { MAO-B } \\
\text { IC }_{\mathbf{9 0}}\end{array}$ & SI \\
\hline $\mathbf{1}$ & $>100$ & NA & $>100$ & 25.18 & 0.84 & $>100$ & $>3.97$ \\
$\mathbf{2}$ & $>100$ & NA & $>100$ & 33.77 & 2.6 & $>100$ & $>2.96$ \\
$\mathbf{3}$ & $>100$ & NA & $>100$ & 45.24 & 1.48 & $>100$ & $>2.21$ \\
$\mathbf{4}$ & $>100$ & NA & $>100$ & 47.64 & 2.9 & $>100$ & $>2.09$ \\
$\mathbf{5}$ & $>100$ & NA & $>100$ & 80.39 & 3.54 & $>100$ & $>1.24$ \\
Clorgyline & 0.0057 & 0.00 & 0.0344 & - & - & - & \\
Deprenyl & - & - & - & 0.0524 & 0.0001 & 0.3586 & \\
Phenelzine & 0.249 & 0.0172 & $>10$ & 0.1528 & 0.0126 & $>1$ & \\
\hline
\end{tabular}

SI: selectivity index of $\mathrm{IC}_{50}$ ratio $\mathrm{MAO} \mathrm{A} / \mathrm{B}$

\subsection{Molecular Modeling}

The docking simulation was carried out for the isolated alkaloids (1-5). Compounds $\mathbf{1}, \mathbf{2}$ and 4 displayed strong to moderate inhibitory activity. These compounds are localized in the hydrophilic zone of the enzyme cavity that faces the FAD (Flavin adenine dinucleotide) molecule. On the other hand, 
compounds $\mathbf{3}$ and $\mathbf{5}$ demonstrated moderate to weak activity and they are placed in the hydrophobic region away from FAD (Figure 5). The results are correlated with the in vitro inhibitory activity.

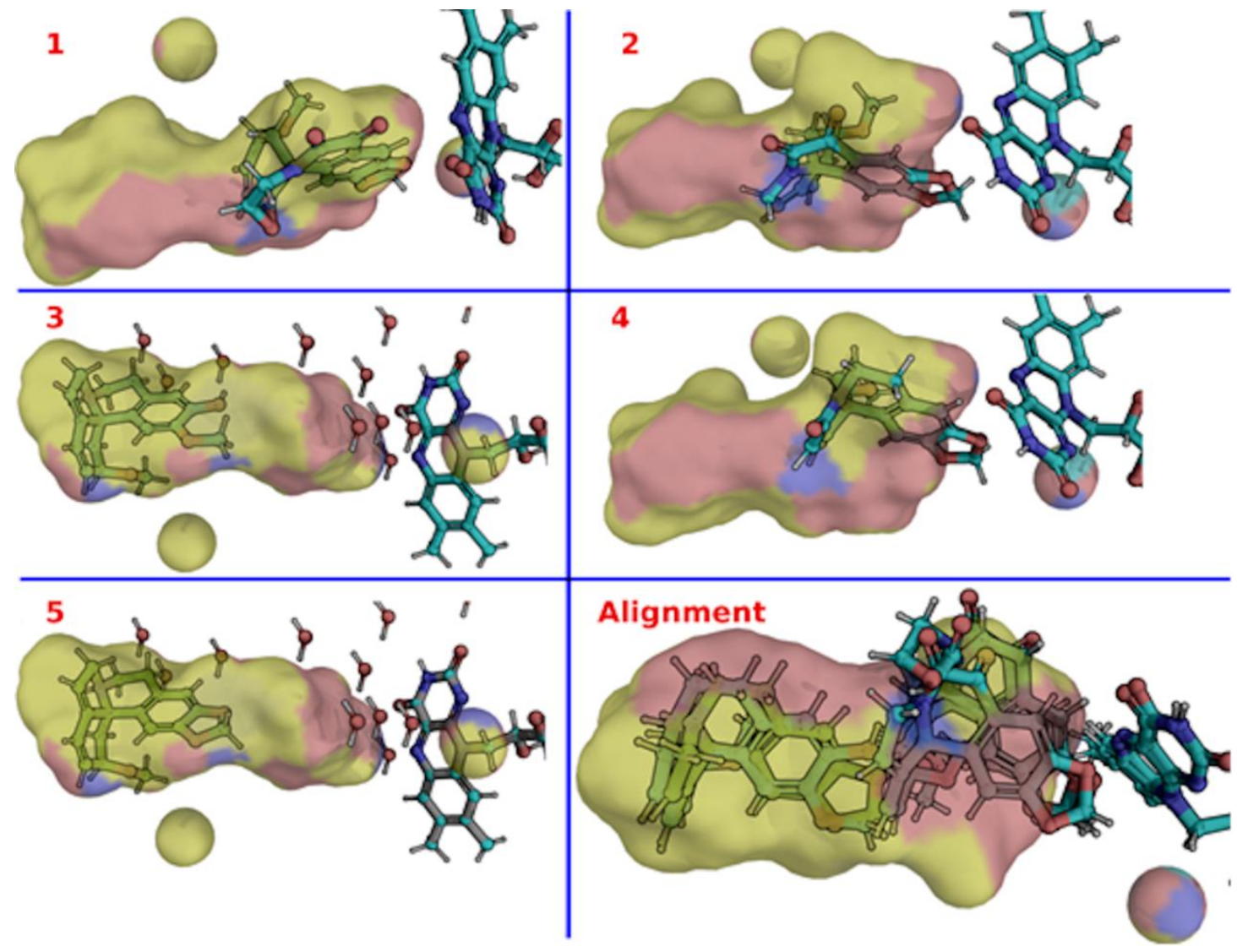

Figure 5. The localization of the isolated alkaloids $(\mathbf{1}, \mathbf{2}$ and $\mathbf{4})$ in the hydrophilic region facing FAD while $\mathbf{3}$ and $\mathbf{5}$ in the hydrophobic region inside MAO-B enzyme cavity

\subsection{Discussion}

The isolated erythrinan alkaloids from E. Corallodendron stems, displayed favourable inhibition against MAO-B without any residual effects against MAO-A. The activity and selectivity displayed direct proportional relationship where the most active compound $\mathbf{1}$ showed the highest selectivity on MAO-B with $\mathrm{IC}_{50} 25.18 \mu \mathrm{M}$, SI $>3.97$ while the least active one $\mathbf{5}$ displayed the least selectivity SI > 1.24. The difference in the activity is related to the structural variations. Direct relationship between the number of oxygen molecules and the inhibitory activity could be detected 1>2>4 $>5$ within the methylenedioxy series. Additionally, the sharp decrease in activity of compound 5 comparing to $\mathbf{4}$ could highlight the essential role of carbonyl functionality within the same series. The substituents effect of erythrinan nucleus was revealed from the molecular docking study. The new alkaloid 1 interacts with FAD. Its methylenedioxy moiety interacts with the water molecules and Tyr435 via strong hydrogen bonds (Figure 6). The presence of the epoxy group improved the interaction pattern by favouring the position of $\mathbf{1}$ in the polar region of the binding site (Figure 5). The 11-oxo group showed hydrogen bond with water molecules. This explains its good activity compared to other compounds in the same series. This interaction pattern has been changed in the subsequent compounds. The lack of the epoxy group shifted the compounds slightly away from the favorable polar region of the active site and away from FAD. The characteristic interaction of $\mathbf{1}$ is observed in compounds $\mathbf{2}$ and $\mathbf{4}$. Further interactions are noticed with the 10-oxo group of compound $\mathbf{2}$, while the absence of these $(10,11)$ dioxo functionality in compound $\mathbf{4}$ and presence of 8-oxo instead shifted the interaction more towards the nonpolar regions and made the compound less active. The lack of any carbonyl groups in case of compounds $\mathbf{3}$ and $\mathbf{5}$ shifted both compounds to the highly hydrophobic area and led to another interaction model more away from FAD (Figure 5), which could explain in part the decrease in activity. However, 
the better interaction of compound $\mathbf{3}$ than $\mathbf{5}$ with the electrostatic region of the ligand pocket could be related to the opening of the methylenedioxy ring to the corresponding $\mathrm{OH}$ and methoxy groups. Different pattern of interaction of erythrinan alkaloids could be deduced from the comparable activity of compounds $\mathbf{4}$ and $\mathbf{3}$ while having different oxygenation functionalities. In addition to our profound results, erythrinan alkaloids was previously reported to have selective inhibition activity against neuronal nicotinic acetylcholine receptors (nAChRs) system [35,36] which is considered a potential strategic target for the management of neurodegenerative diseases AD and PD. The nAChRs in particular $\alpha 7$ subtype play an important role in accumulation of amyloid $\beta$ plaques inside neurons, which is considered the main cause for neuronal deterioration and progress of AD. Antagonists of nAChRs, specially $\alpha 7$ subtype, exhibited prevention of entrance and accumulation of amyloid $\beta$ plaques resulting in neuronal protection [37]. Several erythrinans have been reported to have selective inhibition activity against nAChRs, $\beta$ - Dihydroerythroidine, erysodine, and erythraline displayed selective $\alpha 4, \beta 2$ antagonist activity [36]. Erysodine a common erythrinan alkaloid preferentially antagonizes with high selectivity neuronal nicotinic acetylcholine receptors over the muscarinic type. Also it favourably binds to the high affinity-nicotinic biding site in nAChRs [38]. Erysodine also displayed a high ability to cross blood brain barrier (BBB), which is a favourable drug-like feature for CNS-acting drugs [39]. Additionally, it exhibited the strongest antagonism activity against nAChR $\alpha 4$ and $\alpha 7$ subtypes. A series of synthesized erythrinan alkaloids analogues exhibited selective antagonistic activity towards nAChRs in particular subtypes $\alpha 4, \alpha 3$ and $\alpha 7$ with preferential affinity against the $\alpha 4$ subtype [39]. Also antagonists to the presynaptic nAChRs on the dopaminergic neurons modulate the receptor responsiveness to the acetyl choline which in turn controls the release of DA by decreasing the its response to single pulse and increasing it to burst pulse [40]. Accordingly, erythrinan alkaloids provide a promising lead for development of efficient treatment for AD and PD with synergistic modulation of various neuronal targets. All these together introduces this class of alkaloids as therapeutic useful leads for neurodegenerative disorders, however, extensive pharmacophoric studies are required to enhance the potency and make a good use of their exclusive target selectivity.

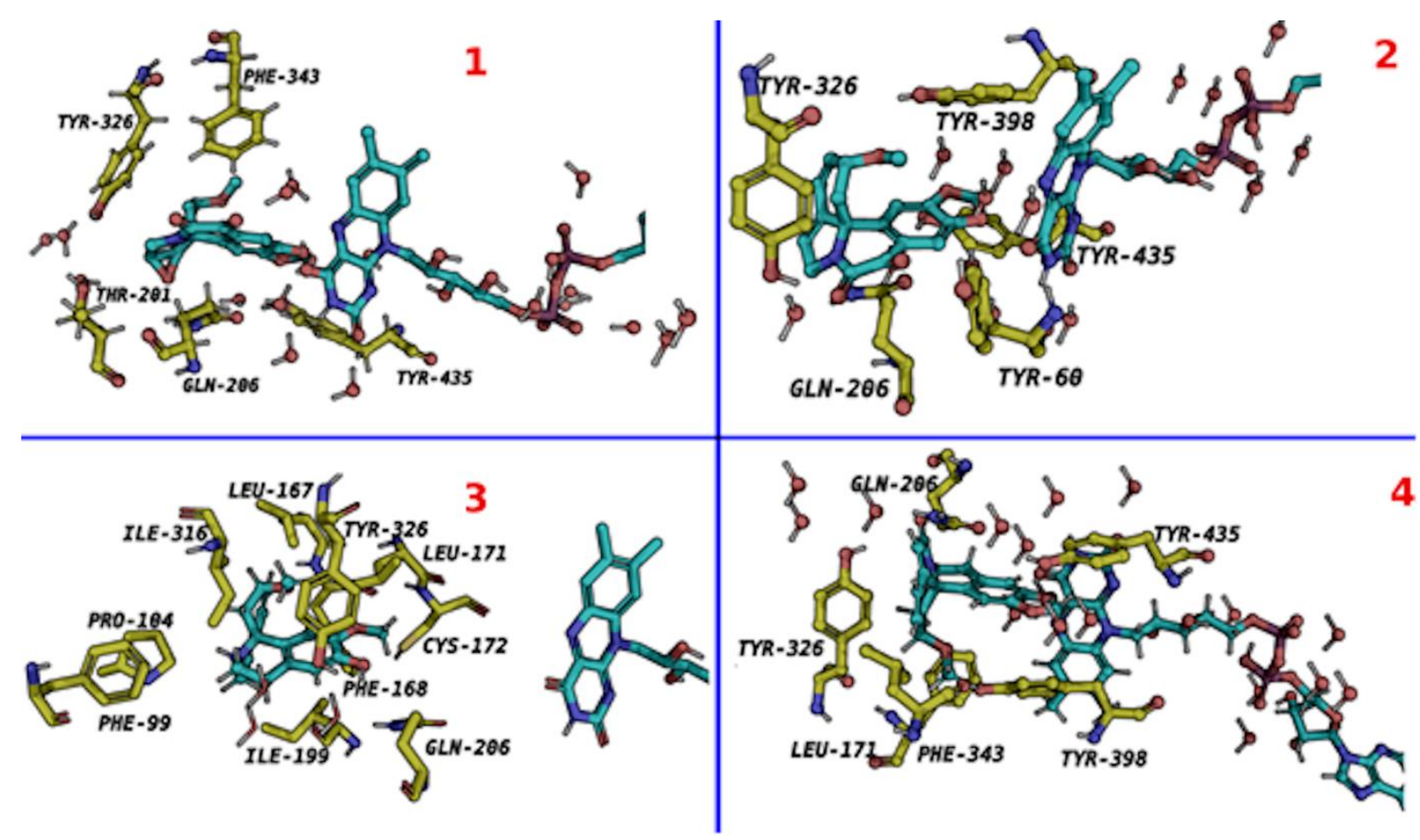

Figure 6. The interaction of alkaloids 1-4 with the surrounding amino acids and water molecules ling MAO-B cavity. 


\section{Conclusion}

In conclusion we report isolation of new erythrinan alkaloid $\mathbf{1}$ for the first time in nature along with four known alkaloids 2-5. Our study also presents erythrinan alkaloids as lead compounds with privilege inhibitory activity against MAO-B which will enhance their performance on AD and PD. The type and degree of oxygenation control the strength of interaction of this class of alkaloids with the FAD partner in the active site of MAO-B and definitely affect compounds activity. Erythrinan alkaloids exhibited their inhibition activity using different pattern of interaction with the surrounding amino acids in the active site of MAO-B enzyme. While methylenedioxy group is common in most active compounds, it was found to be not essential for activity. The replacement of methylenedioxy with $\mathrm{OH}$ and methoxy functional groups increased the activity. The oxygenation at position 10 and 11 seems to be essential for potency. The presence of epoxy function in position 6-7 increases the activity.

\section{Abbreviation}

AD: Alzheimer's disease; CD: circular dichroism; ECD: electronic circular dichroism; PD: Parkinson's disease; MAO: monoamine oxidase; DCM: dichloromethane; $\mathrm{MeOH}$ : methanol; nAChR: neuronal nicotinic acetyl choline receptor; TLC: thin layer chromatography; CC: column chromatography; SI: selectivity index; FAD: Flavin adenine dinucleotide

\section{Acknowledgements}

We are grateful to the Egyptian government and The National Center for Natural Product Research, school of pharmacy, The University of Mississippi and also, AlMaarefa University for the financial support.

\section{Conflict of interest}

The authors declare that they have no conflict of interest.

\section{Supporting Information}

Supporting information accompanies this paper on http://www.acgpubs.org/journal/records-ofnatural-products

\section{ORCID}

Mohamed Aboelmagd: 0000-0003-3527-4872

Khaled M. Elokely: 0000-0002-2394-021X

Ataa Said: 0000-0001-5676-7268

Eman G. Haggag: 0000-0003-4424-160X

Mohammed M. Ghoneim: 0000-0002-9179-4373

Samir A. Ross: 0000-0002-3807-1299

\section{References}

[1] M. Citron (2010). Alzheimer's disease: strategies for disease modification, Nat. Rev. Drug Discov. 9, $387-398$.

[2] M. Amro, S. Teoh, A. Norzana and D. Srijit (2018). The potential role of herbal products in the treatment of Parkinson's disease, Clin Ter. 169, e23-e33.

[3] S. Corbineau, M. Breton, J. Mialet-Perez, J.-F and Costemale-Lacoste (2017). Major depression and heart failure: Interest of monoamine oxidase inhibitors. Int. J. Cardiol. 247, 1-6.

[4] C. Binda, P. Newton-Vinson, F. Hubálek, D.E. Edmondson and A. Mattevi (2002). Structure of human monoamine oxidase B, a drug target for the treatment of neurological disorders, Nat. Struct. Biol. 9, 22-26.

[5] H.H. Fernandez and J.J. Chen (2007). Monoamine oxidase-B inhibition in the treatment of Parkinson's disease, 
Pharmacother. J. Hum. Pharmacol. Drug Ther. 27, 1745-1855.

[6] S. Carradori, M. D’Ascenzio, P. Chimenti, D. Secci and A. Bolasco (2014). Selective MAO-B inhibitors: a lesson from natural products, Mol. Divers. 18, 219-243.

[7] C.D.S. Passos, C. Simoes-Pires, A. Henriques, M. Cuendet, P.-A. Carrupt and P. Christen (2014). Alkaloids as inhibitors of monoamine oxidases and their role in the central nervous system, Stud. Nat. Prod. Chem. 43, 123143.

[8] W.P. Santos, A.C. da Silva Carvalho, C. dos Santos Estevam, A.E.G. Santana and R.M. Marçal (2012). In vitro and ex vivo anticholinesterase activities of Erythrina velutina leaf extracts, Pharm. Biol. 50, 919-924.

[9] I.M. Raupp, A. Sereniki, S. Virtuoso, C. Ghislandi, E.L.C. e Silva, H.A. Trebien, O.G. Miguel and R. Andreatini (2008). Anxiolytic-like effect of chronic treatment with Erythrina velutina extract in the elevated plus-maze test, J. Ethnopharmacol. 118, 295-299.

[10] S.M.M. Vasconcelos, D.S. Macedo, C.T. V Melo, A.P. Monteiro, G. Cunha, F.C.F. Sousa, G.S.B. Viana, A.C.P. Rodrigues and E.R. Silveira (2004). Central activity of hydroalcoholic extracts from Erythrina velutina and Erythrina mulungu in mice, J. Pharm. Pharmacol. 56, 389-393.

[11] S.M.M. Vasconcelos, N.M. Lima, G.T.M. Sales, G.M.A. Cunha, L.M. V Aguiar, E.R. Silveira, A.C.P. Rodrigues, D.S. Macedo, M.M.F. Fonteles and F.C.F. Sousa (2007). Anticonvulsant activity of hydroalcoholic extracts from Erythrina velutina and Erythrina mulungu, J. Ethnopharmacol. 110, 271-274.

[12] O. Flausino, L. de Ávila Santos, H. Verli, A.M. Pereira, V. da S. Bolzani and R.L. Nunes-de-Souza (2007). Anxiolytic effects of erythrinian alkaloids from Erythrina mulungu, J. Nat. Prod. 70, 48-53.

[13] A.C.C.S. Carvalho, D.S. Almeida, M.G.D. Melo, S.C.H. Cavalcanti and R.M. Marçal (2009). Evidence of the mechanism of action of Erythrina velutina Willd (Fabaceae) leaves aqueous extract, J. Ethnopharmacol. 122, 374378.

[14] A.H. Silva, F.N. Fonseca, A.T.A. Pimenta, M.S. Lima, E.R. Silveira, G.S.B. Viana, S.M.M. Vasconcelos and L.K.A.M. Leal (2016).Pharmacognostical analysis and protective effect of standardized extract and rizonic acid from Erythrina velutina against 6-hydroxydopamine-induced neurotoxicity in Sh-Sy5Y cells, Pharmacogn. Mag. 12, 307.

[15] J. Nasimolo, S.G. Kiama, P.K. Gathumbi, A.N. Makanya and J.M. Kagira (2014). Erythrina abyssinica prevents meningoencephalitis in chronic Trypanosoma brucei brucei mouse model, Metab. Brain Dis. 29, 509-519.

[16] T. Shakir, A.Y. Coulibaly and P.G. Kehoe (2013). An exploration of the potential mechanisms and translational potential of five medicinal plants for applications in Alzheimer's disease, Am. J. Neurodegener. Dis. 2, 70.

[17] S.A. Faggion, A.O.S. Cunha, H.A. Fachim, A.S. Gavin, W.F. dos Santos, A.M.S. Pereira and R.O. Beleboni (2011). Anticonvulsant profile of the alkaloids (+)-erythravine and (+)-11- $\alpha$-hydroxy-erythravine isolated from the flowers of Erythrina mulungu Mart ex Benth (Leguminosae-Papilionaceae), Epilepsy Behav. 20, 441-446.

[18] M.E. Garín-Aguilar, J.E. Luna, M. Soto-Hernández, G. Valencia del Toro and M.M. Vázquez (2000). Effect of crude extracts of Erythrina americana Mill. on aggressive behavior in rats., J. Ethnopharmacol. 69, 189-196.

[19] F. Larit, K.M. Elokely, N.D. Chaurasiya, S. Benyahia, M.A. Nael, F. León, M.S. Abu-Darwish, T. Efferth, Y.-H. Wang and D. Belouahem-Abed (2018). Inhibition of human monoamine oxidase A and B by flavonoids isolated from two Algerian medicinal plants, Phytomedicine 40, 27-36

[20] A. E. Nugroho and H. Morita (2014). Circular dichroism calculation for natural products. J Nat Med. 68(1), 1-10.

[21] R. A. Gaussian09, M. J. Frisch, G. W. Trucks and G. A. Petersson (2009). gaussian. Inc., Wallingford CT, 121, 150-166.

[22] J.R. Greenwood, D. Calkins, A.P. Sullivan and J.C. Shelley (2010). Towards the comprehensive, rapid, and accurate prediction of the favorable tautomeric states of drug-like molecules in aqueous solution, J. Comput. Aided. Mol. Des. 24, 591-604.

[23] J.C. Shelley, A. Cholleti, L.L. Frye, J.R. Greenwood, M.R. Timlin and M. Uchimaya (2007). Epik: a software program for $\mathrm{pK}$ a prediction and protonation state generation for drug-like molecules, J. Comput. Aided. Mol. Des. 21, 681-691.

[24] S. Y. Son, J. Ma, Y. Kondou, M. Yoshimura, E. Yamashita and T. Tsukihara (2008). Structure of human monoamine oxidase A at 2.2- $\AA$ resolution: the control of opening the entry for substrates/inhibitors, Proc. Natl. Acad. Sci. U.S.A. 105(15), 5739-5744.

[25] C. Binda, M. Aldeco, W. J. Geldenhuys, M. Tortorici, A. Mattevi and D. E. Edmondson (2012). Molecular insights into human monoamine oxidase B inhibition by the glitazone antidiabetes drugs, ACS Medicinal Chem. Lett. 3(1), 39-42.

[26] G. Madhavi Sastry, M. Adzhigirey, T. Day, R. Annabhimoju and W. Sherman (2013). Protein and ligand preparation: Parameters, protocols, and influence on virtual screening enrichments, J. Comput. Aided. Mol. Des. 27, 221-234.

[27] M.P. Jacobson, R.A. Friesner, Z. Xiang and B. Honig (2002). On the role of the crystal environment in determining protein side-chain conformations, J. Mol. Biol. 320, 597-608.

[28] M.P. Jacobson, D.L. Pincus, C.S. Rapp, T.J.F. Day, B. Honig, D.E. Shaw and R.A. Friesner (2004). A Hierarchical Approach to All-Atom Protein Loop Prediction, Proteins Struct. Funct. Genet. 55, 351-367. 
[29] H. Tanaka, T. Tanaka, H. Etoh, S. Goto and Y. Terada (1999). Two new erythrinan alkaloids from Erythrina $x$ bidwillii, Heterocycles 51, 2759-2764.

[30] M.E. Amer (1993). NMR Spectral Analysis of Five Alkaloids From Erythrina caffra, Alex J.Pharm. Sci. 7, $28-30$.

[31] M.M.D. Mohammed, N.A. Ibrahim, N.E. Awad, A.A. Matloub, A.G. Mohamed-Ali, E.E. Barakat, A.E. Mohamed and P.L. Colla (2012). Anti-HIV-1 and cytotoxicity of the alkaloids of Erythrina abyssinica Lam. growing in Sudan, Nat. Prod. Res. 26, 1565-1575.

[32] A. Saeed and A. Hashem (1997). Phytochemical and biological studies of Erythrina corallodendron Linn: family Leguminosae, Bull. Fac. Pharm. 35, 225-231.

[33] T. Rukachaisirikul, P. Innok and A. Suksamrarn (2008). Erythrina alkaloids and a pterocarpan from the bark of Erythrina subumbrans, J. Nat. Prod. 71, 156-158.

[34] H. Tanaka, H. Etoh, H. Shimizu, T. Oh-Uchi, Y. Terada and Y. Tateishi (2001). Erythrinan alkaloids and isoflavonoids from Erythrina poeppigiana, Planta Med. 67, 871-873.

[35] P. Setti-Perdigão, M.A.R. Serrano, O.A. Flausino, V.S. Bolzani, M.Z.P. Guimarães and N.G. Castro (2013). Erythrina mulungu alkaloids are potent inhibitors of neuronal nicotinic receptor currents in mammalian cells, PLoS One. 8, 8-13.

[36] J.W. Daly (2005). Nicotinic agonists, antagonists, and modulators from natural sources, Cell. Mol. Neurobiol. 25, 513-552.

[37] R.G. Nagele, M.R. D’Andrea, W.J. Anderson and H.Y. Wang (2002). Intracellular accumulation of $\beta$-amyloid142 in neurons is facilitated by the $\alpha 7$ nicotinic acetylcholine receptor in Alzheimer's disease, Neuroscience 110, 199-211.

[38] M.W. Decker, D.J. Anderson, J.D. Brioni, D.L. Donnelly-Roberts, C.H. Kang, A.B. O’Neill, M. Piattoni-Kaplan, S. Swanson and J.P. Sullivan (1995). Erysodine, a competitive antagonist at neuronal nicotinic acetylcholine receptors, Eur. J. Pharmacol. 280, 79-89.

[39] F. Crestey, A.A. Jensen, M. Borch, J.T. Andreasen, J. Andersen, T. Balle and J.L. Kristensen (2013). Design, synthesis, and biological evaluation of erythrina alkaloid analogues as neuronal nicotinic acetylcholine receptor antagonists, J. Med. Chem. 56, 9673-9682.

[40] M.J. Marks, S.R. Grady, T.D. McClure-Begley, H.C. O’Neill and C.A. Zambrano (2014). Presynaptic Nicotinic Acetylcholine Receptors: Subtypes and Functions BT - Nicotinic Receptors, in: R.A.J. Lester (Ed.), Springer New York, New York, NY, pp. 61-91.

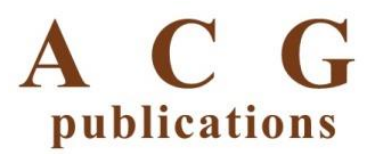

(C) 2021 ACG Publications 